\title{
The Use of The Biological Algorithm in Solving Applied Mechanics Design Problems
}

\author{
Branislav Milenković ${ }^{1)}$ \\ Đorđe Jovanović ${ }^{1)}$
}

\begin{abstract}
Biologically inspired algorithms are becoming powerful in modern optimization. In this paper, the principles of a metaheuristic algorithm based on Harris hawks behavior are shown. The Harris Hawks Optimizer (HHO in short) was used for solving problems in applied mechanics (car side impact, cone clutch, three-dimensional beam and I beam optimization). In the end, a comparison of the results obtained by HHO and results obtained by other methods is given.
\end{abstract}

Key words: Harris hawks, optimization, car side impact, cone clutch, three dimensional beam, I beam.

\section{Introduction}

$\mathrm{B}$ IOLOGICALLY inspired algorithms have been applied in almost every area of science (physics, engineering, microbiology, mathematics, computer science, etc). The most famous biologically inspired metaheuristic algorithms are: Differential evolution (DE), Genetic algorithm (GA), Bat algorithm (BA), Grey Wolf Optimizer (GWO), Ant Colony Optimization (ACO), Grasshopper Optimization Algorithm (GOA), Simulated Annealing (SA), Lion Optimization Algorithm (LOA), etc. In this paper the Harris Hawks'algorithm, one of the biological metaheuristic algorithms created by Heidari [1], will be demonstrated. After the algorithm was published in 2019, it drew researchers' attention, and it was implemented and improved in many areas of expertise.

In the paper that introduces Harris Hawk Optimization algorithm, by Heidari et al. [1], a benchmark set of problems was used to show validity of algorithm use. This benchmark set covers three main groups of benchmark landscapes: unimodal (UM), multimodal (MM), and composition (CM). The UM functions with unique global best can reveal the exploitative (intensification) capacities of different optimizers, while the MM functions can disclose the exploration (diversification) and LO (Local Optimum) avoidance potentials of algorithms. HHO algorithm was also compared to other p-based metaheuristic algorithms, such as Genetic Algorithm (GA), Particle Swarm Optimization (PSO), Biogeography-based optimization (BBO), Flower Pollination Algorithm (FPA), Grey Wolf Optimizer (GWO), Bat Algorithm, Firefly Algorithm (FA), Cuckoo Search (CS), Moth-flame optimization (MFO), Teaching-Learning-Based Optimization (TLBO), Differential Evolution (DE). In almost all test cases, the $\mathrm{HHO}$ algorithm yielded better results than other algorithms.

In this paper, the Harris hawks' algorithm is used to solve the following engineering problems in applied mechanics.
The first problem is automobile side impact optimization problem, with the aim of minimizing total vehicle weight, using eleven design variables. This problem was first subjected in a paper by $\mathrm{Gu}[2]$.

The second engineering problem that will be considered in this paper is optimization of a cone clutch. The goal of this optimization is to minimize the clutch volume. This example was defined in [3].

The third engineering problem that will be considered in this paper is optimization of a three dimensional beam [4]. The goal of this optimization is to minimize cross-section heights for each beam element. This optimization problem is defined by three independent and two dependent variables.

The last engineering problem to be solved is I beam optimization, having the goal of minimizing weight of the beam. This problem was first analyzed and solved by Erfani using modified directed search domain algorithm [5].

\section{Harris hawks algorithm}

The Harris hawk (Parabuteo unicinctus) is a well-known bird of prey that survives in somewhat steady groups found in southern half of Arizona, USA. Based on Louis Lefebvre's research on avian "IQ", this type of bird is one of the most intelligent species of birds found in nature. The key feature of Harris hawk's behavior is that they hunt in groups, which are able to efficiently trace, encircle, flush out, and attack the prey. The main tactic of Harris hawks to capture a prey is a "surprise pounce", which is also known as "seven kills" strategy. This interesting hunting strategy is comprised of several hawks attacking the prey simultaneously from different locations. The hunt may be rapidly completed in one dive, or it may take multiple quick dives during several minutes. The main idea of this tactic is to confuse and drive the prey to exhaustion, increasing its vulnerability (Fig.1).

This algorithm consists of exploration phase, transition to exploitation phase, and exploitation phase.

\footnotetext{
1) Serbian Academy of Sciences and Arts, Mathematical Institute, KnezaMihaila 36, 11000 Belgrade, SERBIA

Correspondence to: Branislav Milenković , e-mail: bmilenkovic@mi.sanu.ac.rs
} 


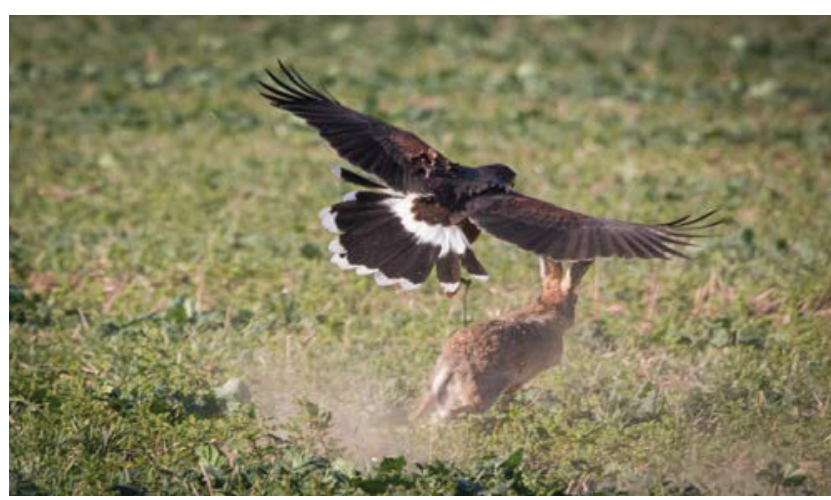

Figure 1. Behavior of a Harris hawk during hunting

In the exploration phase, the hawks perch randomly on some locations, waiting to detect the prey (designated as "rabbit"), which is the current best solution, based on two strategies, each having equal chance $\mathrm{q}$ to be selected. $\mathrm{q}$ is a random variable having the value between 0 and 1 , used for a coin toss in this phase of the algorithm. If this variable's value is less than 0.5, the first strategy is applied. Otherwise, the second strategy is applied. The two fore mentioned strategies are:

$$
X(t+1)=\left\{\begin{array}{c}
X_{\text {radd }}(t)-r_{1}\left|X_{\text {rad }}(t)-2 r_{2} X(t)\right|, q \geq 0.5 \\
\left(X_{\text {rdbbit }}(t)-X_{m}(t)\right)-r_{3}\left(L B+r_{4}(U B-L B)\right), q \leq 0.5
\end{array}\right.
$$

where $X(t+1)$ is hawk position in iteration $t+1, X_{\text {rand }}(t)$ is the position of a randomly selected hawk, $X(t)$ is the hawk's current position, $X_{\text {rabbit }}(t)$ is the current position of the rabbit, $X_{m}(t)$ is the current average position of the hawks. The constants $r_{1}, r_{2}, r_{3}, r_{4}$ are random number inside $(0,1)$ which are updated in each iteration, while UB and LB represent upper and lower bounds of variables. The first strategy generates solutions based on a random position, and the current position of the selected hawk, while the second strategy generates solutions based on current best solution, mean position of all hawks, and the lower and upper bounds for each variable.

Based on escaping energy of the prey, this algorithm switches between the exploration and exploitation phases. This energy is modeled as:

$$
E=2 E_{0}\left(1-\frac{t}{T}\right)
$$

where $E$ indicates the escaping energy of the prey, $\mathrm{T}$ is the maximum number of iterations, and $E_{0}$ is the initial state of its energy. When $|E| \geq 1$, this algorithm is in exploration phase, while for $|E|<1$, the algorithm is in exploitation phase.

In the exploitation phase, the hawks perform the surprise pounce described earlier, by attacking the intended prey. What can happen in this phase is that the prey has enough energy to escape the dive, meaning that the hawks will have to perform several dives on it. This is modeled by the variable $r$, and the prey has equal chances for escaping and not escaping the dive. Whatever the prey does, the hawks will perform a hard $(|E|<0.5)$ or soft $(|E| \geq 0.5)$ besiege.

In case of soft besiege, when $r \geq 0.5$ and $|E| \geq 0.5$, the prey tries to escape the hawks, yet unsuccessfully. This is modeled by the following equations:

$$
\begin{gathered}
X(t+1)=\Delta X(t)-E\left|J X_{\text {rabbit }}(t)-X(t)\right| \\
\Delta X(t)=X_{\text {rabbit }}-X(t)
\end{gathered}
$$

where $\Delta X(t)$ is the difference between the position vector of the rabbit and the current position $t J=2\left(1-r_{5}\right)$ is the random jump strength of the rabbit while trying to run away, and $r_{5}$ is a random variable inside $(0,1)$. In order to simulate the motion of the rabbit, the value $J$ changes randomly in each iteration.

In case of hard besiege, when $r \geq 0.5$ and, $|E|<0.5$ the rabbit does not have enough energy to escape, and the hawks move in for the attack. The positions in this case are updated using the following equation:

$$
X(t+1)=X_{\text {rabbit }}(t)-E|\Delta X(t)|
$$

In case of soft besiege with progressive rapid dives, when $|E|<0.5$ and $r \geq 0.5$, the rabbit has enough energy to escape the attack, while the hawks perform a soft besiege. In order to model the movement of the escaping rabbit, the levy flight concept is used in this algorithm. In order to perform a soft besiege, the hawks decide their next move based on equation:

$$
Y=X_{\text {rabbit }}(t)-E\left|J X_{\text {rabbit }}(t)-X(t)\right|
$$

This result is then compared to the previous dive, to see if this dive will be good or not. If the dive is worse, the hawks perform random rapid dives when approaching the rabbit, based on the following equation:

$$
Z=Y+S x L F(D)
$$

where $D$ is the dimension of problem and $\mathrm{S}$ is a random vector by size $1 x D$ and $L F$ is the levy flight function, which is calculated using the following equation:

$$
L F(x)=0.01 \frac{u x \sigma}{|v|^{\frac{1}{\beta}}}, \sigma=\left(\frac{\Gamma(1+\beta) x \sin \left(\frac{\pi \beta}{2}\right)}{\Gamma\left(\frac{1+\beta}{2}\right) \times \beta \times 2^{\frac{\beta+1}{2}}}\right)^{\frac{1}{\beta}}
$$

The constants $u, v$ are random values inside $(0,1)$, while $\beta$ is the default constant set to 1.5. Based on the previous discussion, the final strategy for updating the hawk position is given by:

$$
X(t+1)=\left\{\begin{array}{l}
Y, \text { if } F(Y)<F(X(t)) \\
Z, \text { if } F(Z)<F(X(t))
\end{array}\right\}
$$

In case of hard besiege with progressive rapid dives, when $|E|<0.5$ and $r \geq 0.5$, the rabbit does not have enough energy to escape, and the hard besiege is performed by the hawks. This time, the hawks try to decrease the distance to their average location with the escaping prey. This is modeled by the following equations:

$$
X(t+1)=\left\{\begin{array}{l}
Y, \text { if } F(Y)<F(X(t)) \\
Z, \text { if } F(Z)<F(X(t))
\end{array}\right\}
$$

where $Y$ and $Z$ are given by the following equations:

$$
Y=X_{\text {rabbit }}(t)-E\left|J X_{\text {rabbit }}(t)-X_{m}(t)\right|
$$




$$
Z=Y+S \times L F(D)
$$

\section{Optimization engineering problems in applied mechanics}

In this section, for each of the optimization problems we describe the basis of the problem, goal function, algorithm parameters, as well as conditions that are to be met. Every step of this process was done using the MATLAB R2019a software suite.

The car (Fig.2) is exposed to a side impact on the foundation of the European Enhanced Vehicle-Safety Committee (EEVC) procedures. The aim is to minimize the total weight of the car using eleven mixed variables.

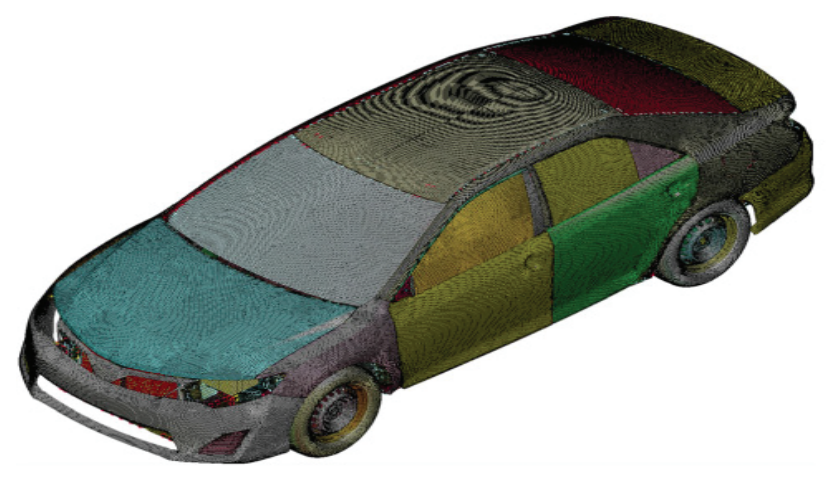

Figure 2. Car model for side impact problem [6]

There are eleven variables that should be optimized: the thickness of the B-Pillar inner $\left(x_{1}\right)$, thickness of the B-Pillar reinforcement $\left(x_{2}\right)$, thickness of the floor side inner $\left(x_{3}\right)$, thickness of the cross members $\left(x_{4}\right)$, thickness of the door beam $\left(x_{5}\right)$, thickness of the door belt line reinforcement $\left(x_{6}\right)$, thickness of the roof rail $\left(x_{7}\right)$, thickness of the materials of Bpillar inner $\left(x_{8}\right)$, thickness of the materials of floor side inner $\left(\mathrm{x}_{9}\right)$, barrier height $\left(\mathrm{x}_{10}\right)$ and hitting position $\left(\mathrm{x}_{11}\right)$.

The problem is reduced to minimization of the function:

$$
\begin{aligned}
f(x)= & 1.98+4.90 x_{1}+6.67 x_{2}+6.98 x_{3}+ \\
& +4.01 x_{1}+1.78 x_{5}+2.73 x_{7}
\end{aligned}
$$

subject to:

$$
\begin{gathered}
g_{1}(x)=F_{a} \leq 1(\mathrm{kN}) \\
g_{2}(x):=V C_{u} \leq 0.32(\mathrm{~m} / \mathrm{s}) \\
g_{3}(x):=V C_{m} \leq 0.32(\mathrm{~m} / \mathrm{s}) \\
g_{4}(x):=V C_{1} \leq 0.32(\mathrm{~m} / \mathrm{s}) \\
g_{5}(x):=\Delta_{u r} \leq 32(\mathrm{~mm}) \\
g_{6}(x):=\Delta_{m r} \leq 32(\mathrm{~mm}) \\
g_{7}(x):=\Delta_{l r} \leq 32(\mathrm{~mm}) \\
g_{8}(x):=F_{p} \leq 4(\mathrm{kN})
\end{gathered}
$$

$$
\begin{gathered}
g_{9}(x):=V_{M B P} \leq 9.9(\mathrm{~mm} / \mathrm{ms}) \\
g_{10}(x):=V_{F D} \leq 15.7(\mathrm{~mm} / \mathrm{ms}) \\
0.5 \leq x_{1}, x_{2}, x_{3}, x_{4}, x_{5}, x_{6}, x_{7} \leq 1.5 \\
-30 \leq x_{10}, x_{11} \leq 30 \\
x_{8}, x_{9} \in\{0.192,0.345\}
\end{gathered}
$$

Variables $F_{a}, V C_{u}, V C_{m}, V C_{1}, \Delta_{u r}, \Delta_{m r}, \Delta_{l r}, F_{p}, V_{M B P}, V_{F D}$ are mathematically described in the paper [6].

The cone clutch problem (Fig.3) must be designed for a minimum volume coupling to two constraints.

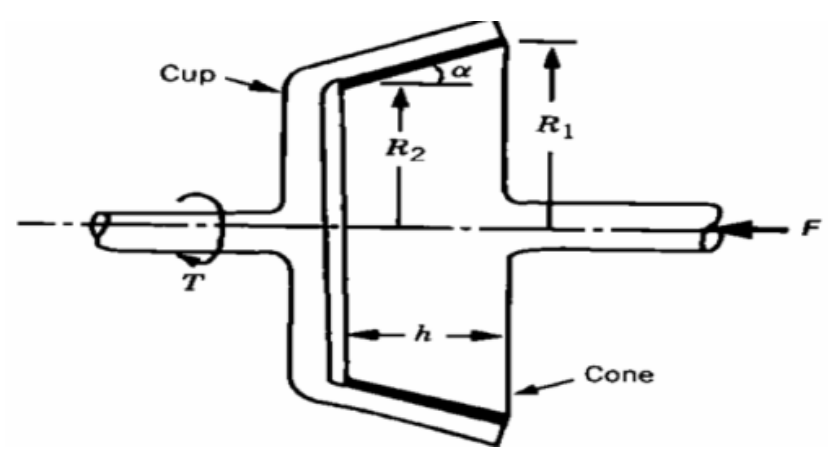

Figure 3. Schematic view of cone clutch with variable parameters [4]

Problem variables are: inner radius of the coupling $R_{1} \equiv x_{1}$ and outer radius of the coupling $R_{2} \equiv x_{2}$

Goal function to be minimized is defined as:

$$
f(X)=\left(x_{1}^{3}-x_{2}^{3}\right)
$$

whilst the conditions to be met are:

$$
\begin{gathered}
g_{1}(X)=\frac{x_{1}}{x_{2}} \geq 2 \\
g_{2}(X)=\frac{\left(x_{1}^{2}+x_{1} x_{2}+x_{2}^{2}\right)}{\left(x_{1}+x_{2}\right)} \geq 5 \\
1 \leq x_{1}, x_{2} \leq 10
\end{gathered}
$$

Third problem consists of minimizing cross-section heights of all elements of a cantilever beam, which is shown in Fig.4. A vertical shift of point $A$ is defined in advance, having a specified upper limit. The beam is under continual load $\left(q_{1}\right.$, $q_{2}$ ) on horizontal parts of the beam, as well as horizontal force $F$, which affects the vertical part of the beam.

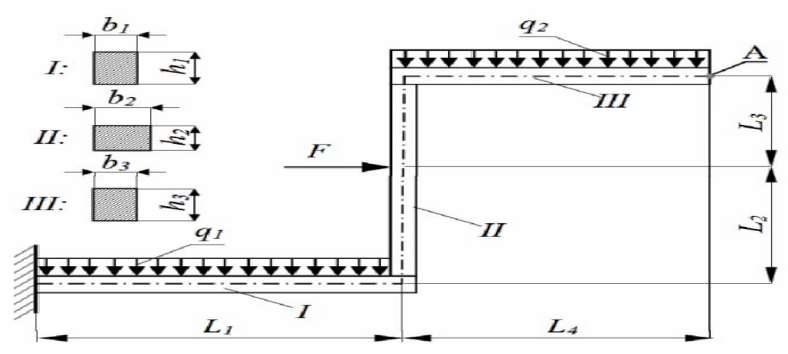

Figure 4. Schematic view of three-dimensional beam with variable parameters [4] 
The problem consists of minimization of the function $f(\boldsymbol{X})=0.8 x_{1}+x_{2}+0.8 x_{3}, \quad$ subject to the following constraints:

$\begin{aligned} u_{A}(\boldsymbol{X}) & =\left[\frac{11.2480 \cdot 10^{-3}}{x_{1}^{3}}+\frac{3.539 \overline{9} \cdot 10^{-3}}{x_{2}^{3}}+\frac{0.3840 \cdot 10^{-3}}{x_{3}^{3}}\right] \\ & \leq 0.05[\mathrm{~m}]\end{aligned}$

$0.1 \leq x_{1} \leq 0.9$

$0.1 \leq x_{2} \leq 0.9$

$$
0.1 \leq x_{3} \leq 0.9
$$

The last problem has four design parameters, related to different longitudinal magnitudes of the I beam (Fig.5).

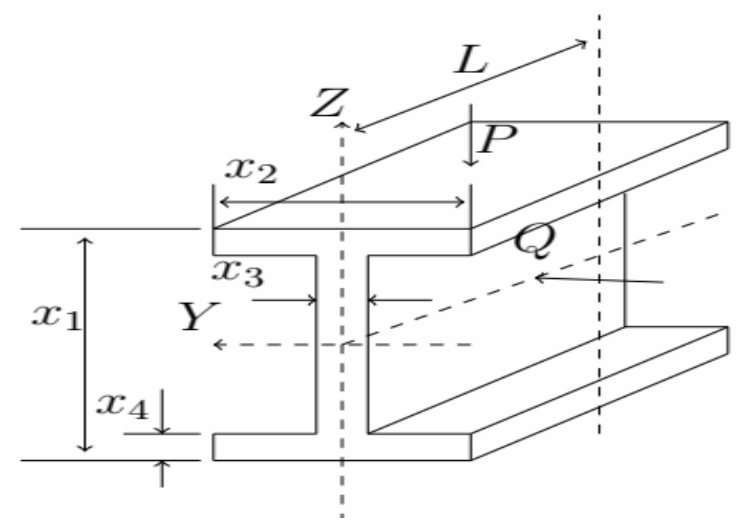

Figure 5. Schematic view of I beam withvariable parameters [5]

The mathematical definition of the problem is:

$$
f_{1}(x)=2 x_{2} x_{4}+x_{3}\left(x_{1}-2 x_{4}\right)
$$

subject to:

$$
\begin{aligned}
& \frac{0.3 P x_{1}}{x_{3}\left(x_{1}-2 x_{4}\right)^{3}+2 x_{2} x_{4}\left[4 x_{4}^{2}+3 x_{1}\left(x_{1}-2 x_{4}\right)\right]}+ \\
& +\frac{0.3 Q x_{2}}{\left(x_{1}-2 x_{4}\right) x_{3}^{3}+2 x_{2}^{3} x_{4}} \leq 0.001 \sigma
\end{aligned}
$$

$$
\begin{aligned}
& 10 \leq x_{1} \leq 80 \\
& 10 \leq x_{2} \leq 50 \\
& 0.9 \leq x_{3} \leq 5 \\
& 0.9 \leq x_{4} \leq 5
\end{aligned}
$$

The constants of this problem are:

$$
P=600 \mathrm{kN}, Q=50 \mathrm{kN}, \sigma=16 \mathrm{kN} / \mathrm{cm}^{2}
$$

\section{Results and discussion}

In this section, the results obtained by using $\mathrm{HHO}$ algorithm on previously defined engineering problems are given. The results of the Harris Hawks Optimization (HHO) algorithm will be compared to the results obtained by the grasshopper optimization algorithm (GOA), cuckoo search (CS), ant colony optimization (ACO), water cycle algorithm (WCA), grey wolf optimization (GWO), whale optimization algorithm (WOA), fuzzy multi-objective optimization (FMO), improved fuzzy multi-objective optimization (IFMO), moth flame optimization (MFO), firefly algorithm (FA), ANSYS, graphic method depending on the solutions found in literature. Based on results shown in Table 1 , a conclusion can be drawn that the objective function having the value of 23.2045, that is obtained using the HHO algorithm, is close to other values found in literature.

Table 1. Comparison of the results for the car side impact problem

\begin{tabular}{||c|c|c|c|c||}
\hline \hline Variables & MFO[7] & GOA $[8]$ & WOA $[9]$ & HHO \\
\hline \hline $\mathrm{x}_{1}$ & 0.5 & 0.5 & 0.5 & $\mathbf{0 . 5}$ \\
\hline $\mathrm{x}_{2}$ & 1.116 & 1.115 & 1.108 & $\mathbf{1 . 2 1 0 8}$ \\
\hline $\mathrm{x}_{3}$ & 0.5 & 0.5 & 0.534 & $\mathbf{0 . 5}$ \\
\hline$x_{4}$ & 1.301 & 1.303 & 1.305 & $\mathbf{1 . 2 3 5 3}$ \\
\hline$x_{5}$ & 0.5 & 0.5 & 0.5 & $\mathbf{0 . 5}$ \\
\hline$x_{6}$ & 1.5 & 1.5 & 1.473 & $\mathbf{1 . 2 2 0 6}$ \\
\hline$x_{7}$ & 0.5 & 0.5 & 0.5 & $\mathbf{0 . 5}$ \\
\hline$x_{8}$ & 0.345 & 0.345 & 0.345 & $\mathbf{0 . 3 4 3 2}$ \\
\hline $\mathrm{X}_{9}$ & 0.345 & 0.286 & 0.192 & $\mathbf{0 . 3 4 3 2}$ \\
\hline $\mathrm{x}_{10}$ & -19.530 & -19.715 & -19.699 & $\mathbf{- 2 . 8 7 7}$ \\
\hline $\mathrm{x}_{11}$ & 0.0000 & 0.320 & 3.481 & $\mathbf{3 . 2 8 4 3}$ \\
\hline$f(x)$ & 22.842 & 22.878 & 23.042 & $\mathbf{2 3 . 2 0 4 5}$ \\
\hline
\end{tabular}

In Fig.6, a convergence diagram for the problem of car side impact problem optimization is given.

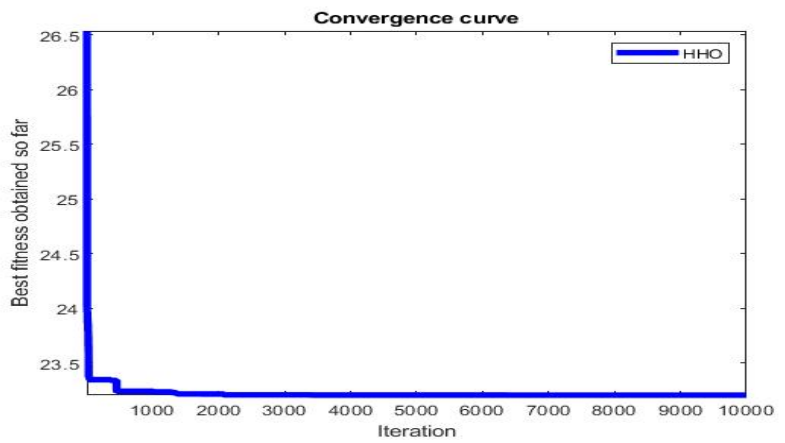

Figure 6. Convergence graph for the best solution for car side impact design

In Table 2, a comparison of the results for a design of a cone clutch optimization problem are shown. Analyzing the table results, a conclusion has been drawn that the $\mathrm{HHO}$ gives better result in comparison to FA, while in comparison to CS and GOA the results are nearly the same.

Table 2. Comparison of the results for the cone clutch problem

\begin{tabular}{|c|c|c|c|c||}
\hline \hline Variables & FA[4] & GWO[10] & CS[4] & HHO \\
\hline \hline $\mathrm{x}_{1}$ & 4.298 & 4.286 & 4.285 & $\mathbf{4 . 2 8 5 7}$ \\
\hline $\mathrm{x}_{2}$ & 2.140 & 2.143 & 2.142 & $\mathbf{2 . 1 4 2 9}$ \\
\hline$f(x)$ & 69.627 & 68.894 & 68.887 & $\mathbf{6 8 . 8 7 7 6}$ \\
\hline
\end{tabular}

In Fig.7, a convergence diagram for the problem of the cone clutch optimization is given.

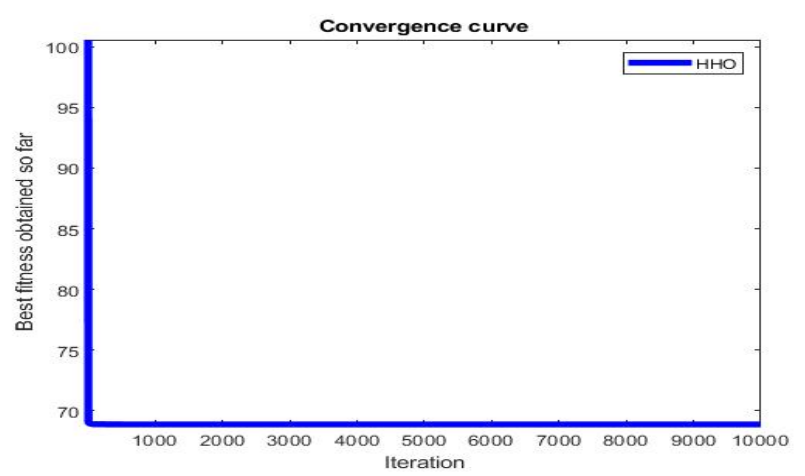

Figure 7. Convergence graph for the best solution for the cone clutch design 
For the three dimensional beam design problem, the results shown in Table 3, along with the results obtained by ANSYS, graphic method and GOA.

Table 3. Comparison of theresults for the three dimensional beam problem

\begin{tabular}{|c|c|c|c|c||}
\hline Variables & ANSYS[11] & GOA[12] & $\begin{array}{c}\text { Graphic } \\
\text { method }[11\end{array}$ & HHO \\
\hline \hline $\mathrm{x}_{1}$ & 0.80458 & 0.80453 & 0.80458 & $\mathbf{0 . 8 0 1 1 7}$ \\
\hline $\mathrm{x}_{2}$ & 0.56993 & 0.56995 & 0.56993 & $\mathbf{0 . 5 7 6 8 5}$ \\
\hline $\mathrm{x}_{3}$ & 0.34585 & 0.34588 & 0.34585 & $\mathbf{0 . 3 4 0 9 9}$ \\
\hline$f(x)$ & 1.4903 & 1.4903 & 1.4903 & $\mathbf{1 . 4 9 0 6}$ \\
\hline
\end{tabular}

Analyzing the table results, a conclusion has been drawn that the HHO gives nearly the same result in comparison to ANSYS (design optimization), graphic method and GOA.

In Fig.8, a convergence diagram for the problem of three dimensional beam optimization is given.

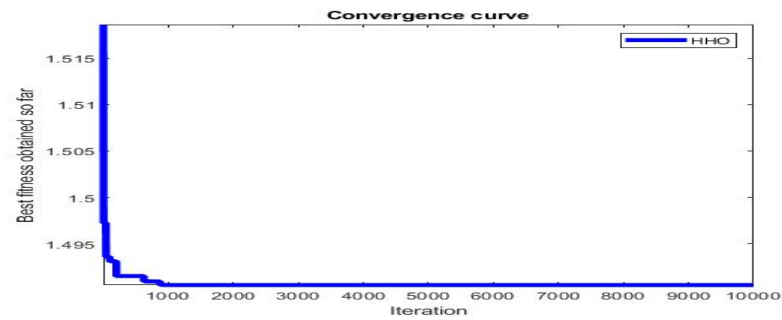

Figure 8. Convergence graph for the best solution for three dimensional beam design

A detailed presentation of the results obtained by theHHO method and comparison of several best results obtained by using other algorithms are given in Table 4.

Table 4. Comparison of the results for the I beam problem

\begin{tabular}{|c|c|c|c|c||}
\hline Variables & ACO [13] & FMO [14] & FMO[15] & HHO \\
\hline \hline $\mathrm{x} 1$ & 79.99 & 80 & 60.4765 & 17.9481 \\
\hline $\mathrm{x} 2$ & 49.99 & 26.1303 & 41.4464 & 29.5209 \\
\hline $\mathrm{x} 3$ & 0.90 & 1.4637 & 0.90 & 0.90 \\
\hline $\mathrm{x} 4$ & 2.390 & 4.7086 & 0.90 & 0.90 \\
\hline$f_{1}$ & 307.53 & 349.3860 & 127.4124 & 67.6709 \\
\hline
\end{tabular}

HHO algorithm achieved better result than Martinez, Hong-Zhong Huang and Hajela.

In Fig9, a convergence diagram for the problem of I beam optimization is given.

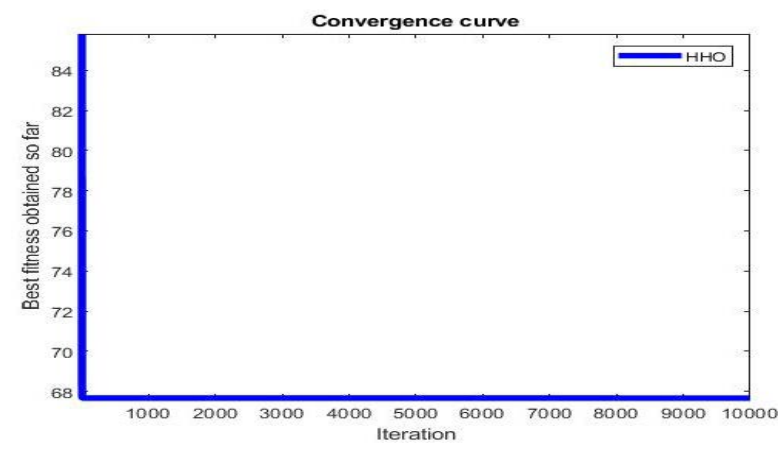

Figure 9. Convergence graph for the best solution for I beam design

\section{Conclusion}

This paper describes the HHO algorithm, as well as its application in few engineering problems. The mentioned engineering problems of car side impact, cone clutch, three dimensional beam and I beam are given in detail, using mathematical formulation and figures, and the results are given in tables.
For this algorithm, 50 search agents and 10000 iterations were chosen as input parameters. During the course of the research, it has been noted that increasing search agent and iteration count did not yield better solutions. Therefore, this combination of input parameters was chosen, since it gives minimal execution time.

In case of I beam optimization, the Harris hawks algorithm gives better results than other methods found in literature. The results for the other three optimization problems, namely the three dimensional beam, cone clutch and car side impact problem, were shown to be near optimal.

\section{Acknowledgement}

This work was supported by the Serbian Ministry of Education, Science and Technological Development through the Mathematical Institute of the Serbian Academy of Sciences and Arts.

\section{References}

[1] ALI ASGHAR HEIDARI, SEYEDALI MIRJALILI, HOSSAM FARIS, IBRAHIM ALJARAH, MAJDI MAFARJA, HUILING CHEN: Harris hawks optimization: Algorithm and applications, Future Generation Computer Systems, March 2019.

[2] GU,L., YANG,R., THO,C., MAKOWSKIT,M., FARUQUET,O., LI,Y:. (2001) Optimization and robustness for crashworthiness of side impact, International Journal ofVehicle Design, Vol. 26, No. 4, pp. 348-360.

[3] SAVSANI,R.V.J.: Mechanical Design Optimization Using Advanced Optimization Techniques, SpringerVerlag London, 2012.

[4] MIODRAGOVIĆ,G.: Advanced bio-inspired algorithms development for solving optimization problems in applied mechanics, doctoral thesis, Faculty of Mechanical and Civil Engineering Kraljevo, University of Kragujevac(2015)

[5] ERFANI,T., UTYUZNIKOV,S.V., KOLO,B.: A modified directed search domain algorithm for multi-objective engineering and design optimization, Structural and Multidisciplinary Optimization, 48(6), 1129-1141, 2013.

[6] T. Kim, M. Cho ,S. Shin, "Constrained Mixed Variable Design Optimization Based on Particle Swarm Optimizer with a Diversity Classifier for Cyclically Neighboring Subpopulations" Mathematics2020, 8, 2016,pp. 1-29.

[7] MIRJALILI,S.: (2015) Moth-flame optimization algorithm: a novel nature-inspired heuristic paradigm. Knowl Based Syst 89:228-249.

[8] MILENKOVIĆ,B., BULATOVIĆ,R., ATANASOVSKA,I.: Application of Grasshopper Algorithm for Solving Optimization Problems in Engineering, X International Conference "Heavy Machinery-HM 2021”, Vrnjačka Banja, 23-25 June 2021.

[9] MIRJALILI,S., LEWIS,A.: The Whale Optimization Algorithm, Advances in Engineering Software, Volume 95, March 2016, pp.51-67.

[10] MILENKOVIĆ,B., KRSTIĆ,M., JOVANOVIĆ,Đ.: Primena algoritma sivog vuka za rešavanje inženjerskih optimizacionih problema, Tehnika, 2021.,Vol.76, Br.1.str.50-57, ISSN 0040-2176.

[11] FEDORIK,F.: Using optimizations algorithms by designing structures, doctoral thesis, Institute of Structural Mechanics, Faculty of Civil Engineering Brno, University of Technology, (2013), pp.119-140.

[12] JOVANOVIĆ,DJ., MILENKOVIĆ,B., KRSTIĆ, M.: Application of Grasshopper Algorithm in Mechanical Engineering,YOURS 2020, pp.1-6.

[13] HAJELA,P., SHIN,C.J.: Multiobjective optimum design in mixed integer and discrete design variables problems, AIAA.J.28 (4), pp.670-675.

[14] MIGUEL MARTINEZ-IRANZO, JUAN,M.HERRERO, JAVIER SANCHIS, XAVIER BLASCO, SERGIO GARCIA-NIETO: Applied Pareto multi-objective optimization by stochastic solvers, Engineering Applications of Artificial Intelligence 22 (2009) pp.455-465.

[15] HONG-ZHONG HUANG, YING-KUI GUB, XIAOPING DUC: An interactive fuzzy multi-objective optimization method forengineering design, Engineering Applications of Artificial Intelligence 19 (2006) pp.451-460. 


\title{
Primena biološki inspirisanih algoritama u rešavanju problema primenjene mehanike
}

\begin{abstract}
Biološki inspirisani algoritmi sve više postaju veoma moćan alat u modernoj optimizaciji. U ovom radu dat je opis metaheurističkog algoritma koji se zasnovan na ponašanju harisovog jastreba. HHO algoritam je korišćen za rešavanje problema primenjene mehanike (bočni udar automobila, konusno kvačilo, trodimenzionalni nosači I nosač). Na kraju rada prikazani su rezultati dobijeni metodom $\mathrm{HHO}$ u odnosu na prethodno dobijene rezultate s adrugim metodama.

Ključnereči: harisov jastreb, optimizacija, primenjena mehanika, bočni udar automobila, konusno kvačilo, trodimenzionalni nosač, I nosač.
\end{abstract}

